\title{
APLIKASI MONITORING SISTEM ABSENSI SIDIK JARI SEBAGAI PENDUKUNG PEMBAYARAN BIAYA PEGAWAI TERPUSAT DENGAN SAP
}

\author{
Ageng Setiani Rafika ${ }^{1}$ \\ Mukti Budiarto ${ }^{2}$ \\ Wahyu Budianto ${ }^{3}$ \\ email: agengsetianirafika@raharja.info,mukti@raharja.info,wahyu.budianto@raharja.info
}

Diterima : 05 November 2104 / Disetujui : 12 Desember 2014

\begin{abstract}
Monitoring Data on the presence of Usig Fingerprints is a strategic approach towards improving the discipline of employees, to achieve improved discipline such officials then needed an application monitoring system using Fingerprint time \&amp; attendance data are not effectively separated the human, infrastructure and overall management system for centralized employee fee payment process with SAP/ERP as expected and did not experience any delay in payment. Attendance System Monitoring application is capable of helping the PA (Payrool Administration) in favour of an increase in the accuracy of the data centralized employee fee payments with SAP can be realized should be supported by a reliable Technology Informatics infrastructure. Attendance Monitoring System application using the Fingerprint are created in this journal is an application programming examples that use the programming language visual basic 6.0 and SQL Server database, which is expected to help resolve problems existing in HUMAN RESOURCES in General and the ADM. Personnel in particular. The design of monitoring data on the presence of using fingerprints only handles input from someone who has been registered in the database, whereas the output that is displayed showing the reports relating to the attendance reports to be used as the supporter of the accuracy of the data centralized employee fee payments with SAP.
\end{abstract}

Keyword: Application Monitoring Attendance, Employee Costs, SAP, Centralized Employee Costs

ABSTRAK

Monitoring Data Kehadiran Menggunakan Sidik Jari merupakan suatu pendekatan strategis terhadap peningkatan disiplin pegawai, untuk mencapai peningkatan disiplin pegawai tersebut maka diperlukan sebuah aplikasi sistem monitoring data absensi menggunakan Sidik Jari yang efektif yang tidak memisahkan antara manusia, sarana prasarana dan sistem manajemen secara keseluruhan agar proses pembayaran Biaya pegawai terpusat dengan SAP/ERP sesuai yang diharapkan dan tidak mengalami keterlambatan dalam pembayarannya. Aplikasi Monitoring Sistem Absensi ini mampu membantu pihak PA (Payrool Administration) dalam mendukung peningkatan keakuratan data pembayaran biaya pegawai terpusat dengan SAP dapat terwujud harus didukung infrastruktur Informatika Teknologi yang andal. Aplikasi Sistem Monitoring Absensi Menggunakan Sidik Jari yang dibuat dalam jurnal ini merupakan suatu aplikasi pemrogaman yang menggunakan bahasa pemrograman visual basic 6.0 dan database SQL Server, yang diharapkan dapat membantu menyelesaikan masalah-masalah yang ada dibagian SDM umumnya dan bagian Adm. Personalia khususnya. Perancangan monitoring data kehadiran menggunakan sidik jari ini hanya menangani input dari seseorang yang mana telah terdaftar dalam database, sedangkan output yang ditampilkan menampilkan laporan yang berhubungan dengan laporan absensi yang dipergunakan sebagai pendukung Akurasi data pembayaran Biaya pegawai terpusat dengan SAP.

Kata Kunci : Aplikasi Monitoring Absensi, Biaya Pegawai, SAP, Biaya Pegawai Terpusat 


\section{PENDAHULUAN}

Untuk mensejajarkan diri dengan perusahaan - perusahaan penyedia listrik tingkat dunia, PT PLN (persero) mengimplementasikan Enterprise Resource Planning (ERP), sistem yang mengintegrasikan seluruh elemen-elemen pada perusahaan termasuk unit-unit bisnis yang diakomodasikan oleh IT. Penerapan ERP ini diharapkan akan meningkatkan kompetensi perusahaan dan secara otomatis akan meningkatkan pelayanan. Penerapan ERP ini akan mengintegrasikan seluruh kantor PLN baik pusat maupun daerah secara on-line, dan seluruh kantor PLN tersebut akan terstandarisasi.

Dengan penerapan ERP di lingkungan perusahaan, maka setiap pegawai diharuskan untuk beradaptasi dengan perubahan sistem yang terjadi. Pengimplementasian ERP jelas akan merubah pola kerja suatu perusahaan

Ide penerapan ERP di PT PLN (persero) telah direncanakan dengan sangat matang seperti dikemukakan oleh Direktur Strategi Teknologi Informasi PT. PLN (persero), "penerapan ERP dan rencana kerja PLN sejalan dan telah tertuang di dalam sinkronisasi IT master plan dan strategi bisnis PLN".

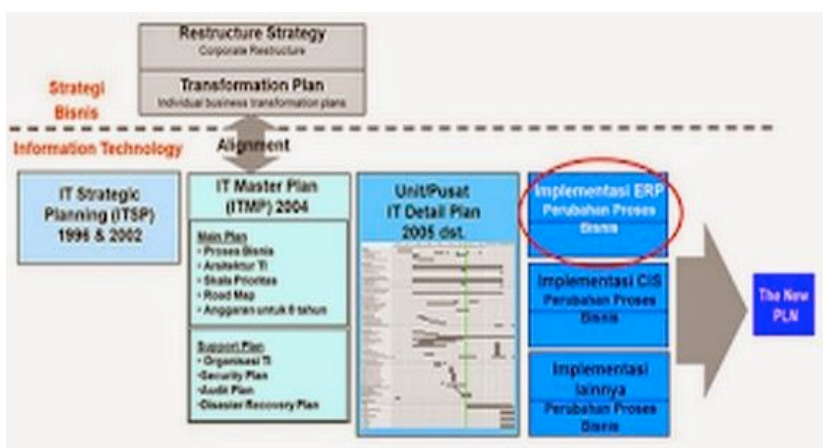

Gambar 1. Strategi Bisnis Information Technology PT.PLN Sebagai Dasar Implementasi ERP/SAP PT.PLN (Persero)

ERP merupakan satu kesatuan dengan Strategi Utama PLN dalam membenahi operasional perusahaan secara keseluruhan. Penerapan ERP saat ini masih bersifat Pilot Project dan baru dilaksanakan

di empat unit yaitu: Kantor pusat PLN di jakarka, Kantor Distribusi Bali, kantor distribusi Jakarta Raya dan Tangerang, dan P3B Jawa Bali.

"Go-Live" ERP tahap I di PT PLN (persero) dilakukan pada tanggal 29 Desember 2005, terutama diterapkan modul-modul untuk menunjang bisnis proses di bagian Sumber Daya Manusia(SDM) seperti manajemen organisasi, administrasi kepegawaian, penggajian dan waktu kerja karyawan.

Penerapan ERP akan mendahulukan kantor yang telah menerapkan sistem pelayanan pelanggan terlebih dahulu, karena PLN sangat concern atas pelayanan pelanggan. jadi, integrasi antar sistem ini akan dilakukan lebih dulu di Jawa Barat, Jawa Tengah dan Jawa Timur, karena di daerahdareah tersebut yang paling siap akan penerpan integrasi antar sistem tersebut.

Kesulitan yang paling besar dari penerapan ERP adalah "People." Sesempurna apapun rancangan dan penerapan ERP, tidak akan berguna apabila tidak didukung oleh seluruh pegawai. Dibutuhkan kemauan yang besar dari seluruh pegawai untuk beradaptasi dengan perubahan sistem yang selama ini telah berjalan.menurut ketua tim Change Management Proyek Implementasi ERP, Rully Fasri, kendala terbesar dalam menerapkan ERP adalah merubah pola pikir yang selama ini terbentuk dari seluruh karyawan untuk menerima sebuah perubahan. Tanpa adanya pola pikir yang baru, menurut Rully, ERP tidak akan memberikan manfaat bagi perusahaan.

IT Master Plan PLN dibuat pada tahun 2004, bentuk riil PLN dari rencana tersebut adalah mengembangkan IT secara bertahap ditubuh PLN, seperti membangun sistem informasi secara on-line menghubungkan kantor pusat dan kantor cabang yang centralized serta membangun sistem 
jaringan yang handal untuk mendukung pembangunan Sistem tersebut.

Pada tahap awal penerapan ERP, PLN menerapkan di tiga bidang yaitu: divisi keuangan, divisi logistik dan divisi sumberdaya manusia. Ujicoba Pilot project dilakukan di kantor PLN distribusi Jakarta Raya \& Tangerang, distribusi Bali, dan kantor Penyaluran dan Pusat Pengaturan Beban Jawa-Bali.

Dengan pertimbangan khusus, PLN memilih SAP sebagai paket perangkat lunak ERP, dan bekerja sama dengan Accenture sebagai perusahaan konsultan penerapan ERP. Bisnis Proses PLN yang sangat spesifik dan berbeda dari perusahaan listrik di dunia yang lain, maka beberapa modul pada sistem ERP perlu di sesuaikan dengan kebutuhan dari PLN itu sendiri.

Untuk mendukung Strategi Bisnis PLN, maka diperlukan solusi ERP yang akan diimplementasikan ke seluruh unit PLN. Hal ini sesuai dengan Perencanaan IT Master Plan PLN (ITMP) dimana ERP merupakan salah satu alat untuk melakukan transformasi PLN menjadi perusahaan listrik kelas dunia yang cost competitive.

Beberapa hal yang menjadi alasan implementasi SAP ERP di PT. PLN (Persero) antara lain :

PT. PLN (Persero) membutuhkan standarisasi proses bisnis melalui sistem "back office" yang terpadu (integrated system)

- Untuk mengadopsi Utility Best Practices

- PT. PLN (Persero) Mendapatkan pengoperasian dan mekanisme pengawasan dan pengendalian proses bisnis yang lebih baik dengan adanya sistem "back office" yang standard

- Untuk memperoleh akses informasi dari unit-unit bisnis terkait secara real time
Saat ini Implementasi SAP ERP di PT. PLN (Persero) sudah meliputi seluruh Unit Pelaksana/Unit Pelaksana Induk di PT. PLN (Persero)

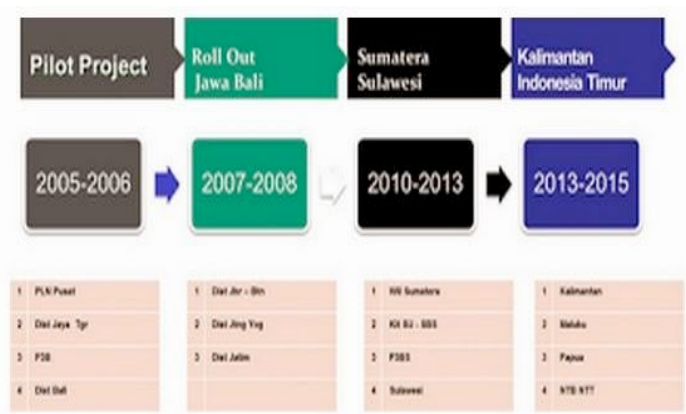

Gambar 2. Roll Out ERPHistorical and Plan

\section{PERMASALAHAN}

Modul Human Resources (HR) ini menitikberatkan pada kebutuhan akan penilaian kepada pegawai PT PLN (Persero). Dimana modul ini menggantikan system lama yaitu Sistem Informasi Pegawai (SIPEG) yang masih manual. Cakupan dalam modul HR ini meliputi proses perekrutan karyawan, sistem kepangkatan atau golongan, mengukur tingkat kinerja karyawan, pemberian penghargaan atau teguran (punishment and rewards), system penggajian pegawai sesuai dengan pangkat atau golongan (payroll), pengajuan ijin cuti, hingga pada penghitungan masa pensiun pegawai. Masih terdapat beberapa fungsi lain dalam modul HR ini yang dapat diterapkan oleh PLN guna meningkatkan kepedulian terhadap kebutuhan setiap pegawai. Dengan begitu setidaknya dapat memberikan pandangan yang bersifat obyektif untuk setiap pegawai karena setiap pegawai diukur berdasarkan kinerja yang dilakukan bukan karena persepsi pribadi beberapa pihak saja, hingga dapat membantu bagian Sumber Daya Manusia (SDM atau HRD) di PLN dalam memberikan penilaian kepada tiap pegawai yang bersifat obyektif. 
Dalam membangun IT (Information Technology) terdapat 4 pilar penting yaitu Hardware, Software, Network dan Data yang tidak dapat terpisahkan dan saling berkaitan. Hubungan ke empat pilar tersebut dijelaskan sebagai berikut dengan bagan dibawah ini :

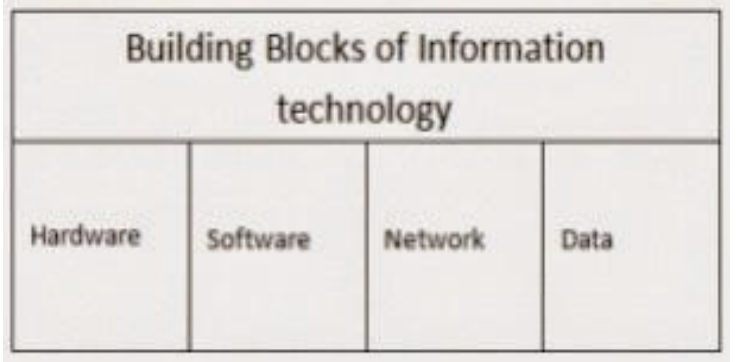

Tabel 1. 4 Pilar Teknologi Informasi

Seluruh pilar-pilar diatas yaitu hardware, software, network dan data merupakan hal yang tidak dapat dipisahkan karena semuanya saling berkaitan dalam membangun suatu teknologi informasi yang dimanfaatkan oleh pengguna komputer diseluruh dunia. Hardware merupakan perangkat keras yang dapat dilihat dan nyata yang digunakan untuk membangun infrastruktur komputer dan jaringannya, serta software yang digunakan untuk menganalisa, mengelola dan memanajemen agar setiap hardware dapat saling berkomunikasi. Kemudian jaringan yang digunakan agar setiap komputer yang ada diseluruh dunia dapat saling berkomunikasi dan dapat melakukan pertukaran data dan informasi sesuai kebutuhan pengguna computer, serta sekumpulan data yang diolah dan dimanagement dalam sistem informasi agar dapat menghasilkan informasi yang dimengerti manusia. Sehingga data yang dimiliki dapat dimanfaatkan oleh pengguna komputer.

Berdasarkan analisa yang dilakukan dalam latar belakang diatas penelitian ini secara jelas berkaitan dengan Aplikasi Monitoring Sistem Absensi Sebagai Pendukung Keakuratan Data Pembayaran Biaya Pegawai Terpusat Dengan SAP. Dimana dari segi IT masih sangat lemah. Mulai dari terdapatnya sistem yang masih manual menyebabkan ketidak akuratan dalam mempersiapkan data pendukung dan seringnya error aplikasi SAP pada saat simulation / running pembayaran biaya pegawai oleh Unit Pelaksana Induk sehingga pembayan gaji kepada pegawai akan mengalami keterlambatan yang berdampak menurunnya motivasi kerja pegawai.

Pada saat ini PT.PLN (Persero) P3B JB APP Durikosambi memiliki suatu metode monitoring absensi yang mutakhir. PT.PLN (Persero) P3B JB APP Durikosambi telah membuat terobosan baru dalam metode monitoring absensi yaitu dengan menggunakan mesin fingerprint yang sangat bermanfaat bagi karyawan, bagian SDM dan Administrasi serta manajemen/atasan Namun masih mengalami hambatan dalam implementasinya. yaitu :

1. Adanya kesalahan dalam memasukan data pegawai misalnya salah memasukan nomor induk pegawai yang mengakibatkan terjadinyagagal upload dalam program system application andproductin data processing (SAP) ,dan mengakibatkan prosespembuatan gaji terhambat.

2. keterlambatan dokumen yang digunakan sebagai dasar pelaporan.

3. Jaringan yang terkadang error apabila program system application and productin data processing (SAP) tersebut sering digunakan, sehingga akan menghambat pekerjaan para SDM dalam posting atau input data biaya pegawai ke bagian keuangan unit pelaksana induk / dalam unit pelaksana itu sendiri.

4. Keterbatasan pegawai dalam menggunakan bahasa asing yang terdapat dalam program system application andproductin data processing (SAP). 


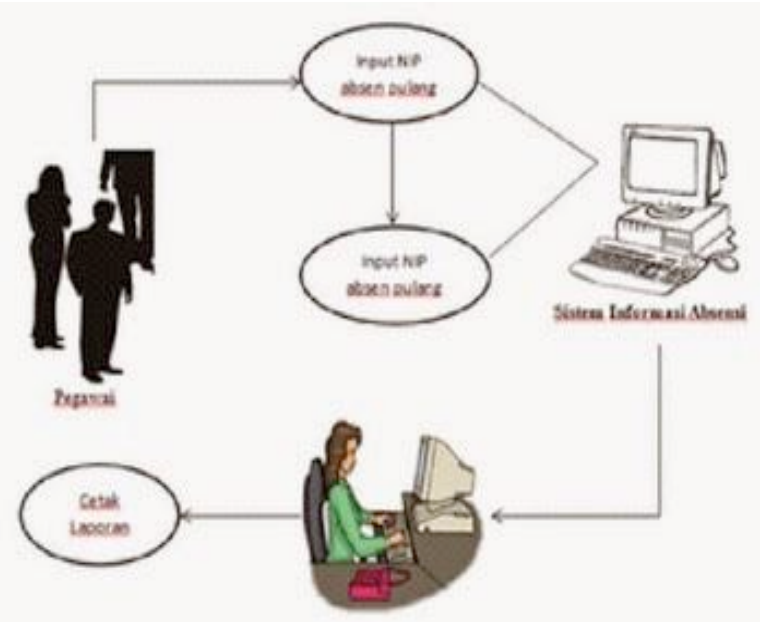

Gambar 3 Siklus Pembuatan Daftar

Potongan Ketidakhadiran pada Tunjangan P2 / P2 Tambahan

\section{LITERATURE REVIEW}

Menurut Hasibuan, Literature review berisi tentang uraian teori, temuan dan bahan penelitian lain yang diperoleh dari bahan acuan untuk dijadikan landasan kegiatan penelitian. Uraian dalam Literature review ini diarahkan untuk menyusun kerangka pemikiran yang jelas tentang pemecahan masalah yang diuraikan sebelumnya pada permusan masalah.

Literature review berisi ulasan, rangkuman, dan pemikiran penulis tentang beberapa sumber pustaka (dapat berupa artikel, buku, slide, informasi dari internet, dan lain-lain) tentang topik yang dibahas, dan biasanya ditempatkan pada bab awal. Hasil-hasil penelitian yang dilakukan oleh peneliti lain dapat juga dimasukkan sebagai pembanding dari hasil penelitian yang akan dicobakan disini. Semua pernyataan dan/atau hasil penelitian yang bukan berasal dari penulis harus disebutkan sumbernya, dan tatacara mengacu sumber pustaka mengikuti kaidah yang ditetapkan. Suatu literatur review yang baik haruslah bersifat relevan, mutakhir (tiga tahun terakhir), dan memadai.
Fokus utama suatu tinjauan pustaka atau literature review dalam suatu penelitian adalah mengetahui apakah peneliti lain telah menemukan jawaban untuk pertanyaan-pertanyaan penelitian tersebut dalam berbagai pustaka atau laporan hasil penelitian yang paling aktual, maka kita tidak perlumelakukan oenelitian yang sama.

\section{Langkah-langkah Melakukan Kajian Literature Review}

Metode Literature Review ini dilakukan untuk menunjang metode observasi yang telah dilakukan. Pengumpulan informasi yang dibutuhkan dalam mencari referensireferensi yang berhubungan dengan penelitian yang dilakukan.Dalam melakukan kajian literature review ini, langkah-langkah yang harus dilakukan (Suryo dkk, 2010:87) sebagai berikut :

1. Mengidentifikasikan

kesenjangan (identify gaps) dari penelitian ini.

2. Menghindari membuat ulang (reinventing the wheel) sehingga banyak menghemat waktu dan juga menghindari kesalahankesalahan yang pernah dilakukan oleh orang lain.

3. Mengidentifikasikan

metode yang pernah dilakukan dan yang relevan terhadap penelitian ini.

4. Meneruskan capaian penelitian sebelumnya sehingga dengan adanya studi pustaka ini, penelitian yang akan dilakukan dapat dibangun di atas platform pengetahuan atau ide yang sudah ada.

5. Untuk mengetahui orang lain yang spesialis dan mengerjakan di area penelitian yang sama, sehingga dapat terjaring dalam komunitas yang dapat memberi kontribusi sumber daya yang berharga. 
Banyak penelitian yang sebelumnya dilakukan mengenai Aplikasi Monitoring Absensi Sebagai Pendukung Keakuratan Data Pembayaran Biaya Pegawai Dengan SAP Pada PT.PLN (Persero) APP Durikosambi dan penelitian lain yang berkaitan. Dalam upaya mengembangkan dan menyempurnakan penerimaan mahasiswa baru secara "online" ini perlu dilakukan "study" pustaka "(literature review)" sebagai salah satu dari penerapan metode penelitian yang akan dilakukan. Diantaranya yaitu:

1. Lud Rudy Anggoro dari PT.PLN (Persero) UIP Jaringan Sumatera I dalam TSnya berjudul "Analisa Tingkat Absensi Terhadap Produktivitas Kerja dan Penentuan P3-1". Penulis dalam Telaan Stafnya ini membahas tentang Penggunaan teknologi untuk perusahaan sebagai acuan efektivitas kinerja adalah pengadaan sistem terkomputerisasi dalam aktivitas kerja salah satunya adalah sistem absensi handkey machine. Sistem Manajemen Absensi merupakan fasilitas untuk mengelola, memantau, serta menghasilkan laporan-laporan cuti dan absensi yang dapat digunakan untuk melihat perilaku absensi pegawai serta melihat produktivitas kerja pegawai

2. Kartika Elisabeth, Eka Widhi Yunarso, Budi Laksono Putro dari Politeknik Telkom Bandung yang berjudul "Jurnal Sistem Informasi Absensi dan Penggajian Pegawai". Penelitian ini membahas mengenai pengembangan sistem absensi dan penggajian. Pada penelitian ini sistem yang dikembangan menggunakan bahasa pemograman Java dan client server sebagai arsitektur dimana client sebagai perangkat yang menerima dan menjalankan aplikasi sedangkan server perangkat yang menyediakan dan bertindak sebagai pengolah aplikasi data dan keamanannya. Kelebihan dari sistem ini memiliki sistem absensi yang berkaitan dengan penggajian, dimana sistem penggajian yang dibuat bisa memberikan laporan yang cepat dan akurat. Adapun kekurangan dari sistem ini adalah tidak adanya menu report (laporan) tentang absensi dan penggajian yang dapat ditampilkan secara lengkap perhari, perminggu, bulan ataupun pertahun.

3. Penelitian ini dilakukan Rachman Mulyandi, Cynthia Ayu Wulan Dini dari Perguruan Tinggi Raharja, pada tahun 2014 yang berjudul Aplikasi Absensi Pegawai Kecamatan Batuceper TangerangDalam Meningkatkan Akurasi Informasi. Pada penelitian ini membahas tentang sistem informasi absenisi yang ada pada Kecamatan Batuceper proses absensi yang berjalan yang ada saat ini masih dilakukan secara manual dalam hal proses pengolahan data absensi pegawai. Maka dari itu sering terjadi kecurangan pada proses absensi seperti penitipan absen dan pulang sebelum jam kerja berakhir. Proses pengolahan data yang lambat dapat mengakibatkan lambatnya penyampaian informasi. Oleh sebab itu diperlukan sistem infromasi yang dapat memecahkan masalah tersebut yang cepat dan akurat. Penulis mengusulkan sistem informasi absensi yang dapat membantu para pegawai dalam melakukan absen, terutama pada bagian kepegawaian yang akan sangat membantu dalam proses pengolahan data absensi. Dimana sistem yang dibangun ini pada proses absensinya hanya memasukkan NIP pada saat absen, 
dan secara otomatis akan terdaftar pada tabel absensi pegawai

4. Catur Fifty Anas Sari, LiesYulianto dari Universitas Surakarta berjudul "Perancangan Sistem Informasi Absensi Menggunkaan Finger Print di Badan Perencanaan Pembanguna Daerah dan Penanaman Modal Kabupaten Pacitan". Permasalahan yang ada pada sistem absensi pegawai di Badan Perencanaan Pembangunan Daerah dan Penanaman Modal Kabupaten Pacitan masih dilakukan secara manual dengan melakukan absensi tanda tangan pada kertas dan juga terdapat kecurangan para pegawai yang menitipkan tanda tangan absensinya. Dari permasalah tersebut maka dibuatlah sistem absensi menggunakan finger print dengan tujuan untuk menerapkan aplikasi yang mudah digunakan dengan hasil yang maksimal dan cara pemakaiannya yang mudah. Pembuatan aplikasi ini menggunakan data base sebagai proses penyimpan data. Kelebihan dari sistem ini dapat meningkatkan kedisiplinan dalam mengemban tugas

5. Penelitian Skripsi oleh Joko Supriyono dari Perguruan Tinggi Raharja pada tahun 2014 yang berjudul "Perancangan Sistem Informasi Absensi Karyawan Menggunakan Konsep Data Mining Pada PT. Kalila Indonesia”. Penelitian pada sistem absensi karyawan di PT Kalila Indonesia yang sedang berjalan saat ini masih belum efektif, karena dalam pengolahan datanya dilakukan dengan cara manual dan banyak ditemukan kekurangan-kekurangan seperti hilangnya arsip data karyawan, kesalahan menginput data, kesalahan penulisan, dan lamanya waktu yang dibutuhkan, sehingga mengakibatkan data yang dihasilkan belum akurat. Berdasarkan hasil analisa, diperlukan suatu sistem yang dapat memfasilitasi kegiatan absensi melalui sistem informasi absensi berbasis web sehingga data absensi dapat tersimpan dengan baik pada suatu database.[5]

6. Penelitian Skripsi oleh Dhita Rukmianti dari Perguruan Tinggi Raharja pada tahun 2009 yang berjudul "Pengembangan Sistem Informasi Absensi Karyawan Pada Perguruan Tinggi Raharja".Penelitian ini membahas usulan untuk memperbaiki kekurangan yang ada pada sistem yang sedang berjalan dimana sistem belum mampu menyediakan informasi yang dibutuhkan dengan cepat karena masih menggunakan sistem manual. Proses absensi yang diusulkan menggunakan sistem terpusat sehingga hasil dari proses sistem informasi dapat sesuai dengan yang diharapkan, dan dapat lebih meningkatkan kinerja manajemen dalam kedisiplinan karyawan yang lebih efektif untuk mengetahui peningkatan tentang diri karyawan berdasarkan data absensinya.

7. UU Republik Indonesia NO 132003 Tentang Ketenagakerjaan

8. SK Direksi No SK.1364.K.DIR.2011 Tentang Implementasi Pemusatan Pengelolaan Fungsi Administrasi Keuangan, Administrasi Sumber Daya Manusia dan Administrasi Umum Dari Unit Pelaksana ke Unit Pelaksana Induk.

9. Edaran Direksi No 014.E/DIR/2011 Tanggal 17

Oktober 2011 Tentang Pedoman Implementasi Pemusatan Pengelolaan Fungsi Administrasi Keuangan, Administrasi Sumber Daya Manusia dan Administrasi 
Umum Dari Unit Pelaksana ke Unit Pelaksana Induk

10. Modul SAP HR PT.PLN (Persero)

Dari 10(sepuluh) literature review yang ada, masih banyak penelitian mengenai Aplikasi Monitoring Sistem Absensi Sebagai Pendukung Akurasi Data Pembayaran Biaya Pegawai Terpusat Dengan SAP Oleh karena itu, untuk menindaklanjuti penelitian sebelumnya seperti yang dikemukakan diatas, maka dilakukan penelitian Aplikasi Monitoring Sistem Absensi Sebagai Pendukung Akurasi Data Pembayaran Biaya Pegawai Terpusat Dengan SAP Pada PT.PLN (Persero) APP Durikosambi.

\section{Metode Penelitian}

1. Tahapan Pengumpulan Data

Menurut Rapina (2011:15) ${ }^{1}$, teknik pengumpulan data, yaitu:

a. Studi Lapangan

Yaitu penelitian yang dilakukan secara langsung pada perusahaan yang bersangkutan untuk memperoleh data primer dan informasi yang dibutuhkan, dengan cara :

b. Observasi

Observasi merupakan suatu teknik yang digunakan untuk mengumpulkan data dengan cara melakukan pengamatan secara langsung ke tempat yang dijadikan objek penelitian.

c. Wawancara

Wawancara merupakan salah satu teknik untuk mengumpulkan data dengan cara menanyakan secara langsung kepada pihak yang berkaitan dengan penelitian.

\section{d. Dokumentasi}

Dokumentasi adalah suatu teknik pengumpulan data dengan cara mengumpulkan semua hal yang diperlukan yang dapat menunjang keberhasilan penelitian.

\section{Studi Kepustakaan}

Yaitu mencari dan mengumpulkan bahan yang berhubungan dengan masalah yang diteliti untuk memperoleh data sekunder dengan membaca, mempelajari, dan mendalami literatur-literatur yang berhubungan dengan masalah yang diteliti.

\section{PEMECAHAN MASALAH}

Adapun Proses Pembayaran Biaya Pegawai Terpusat yang dilaksanakan oleh PTPLN (Persero) P3B Jawa Bali APP Duri kosambi adalah sebagai berikut:

1. Pembayaran Penghasilan Pegawai Proses pembayaran PayforPerson (P1), Payfor Position(P2), Payfor Performance (P3), Tunjangan Cuti Tahunan/Besar, Tunjangan Winduan, UPPG, THR, dan Bonus/lnsentif Kinerja kepada pegawai pembayarannya dilakukan di UPI melalui sistem ERP PLN. Proses pembayaran penghasilan pegawai diawali dari proses penghitungan penghasilan pegawai dan diakhiri dengan proses transfer penghasilan kerekening bank pegawai

2. Pembayaran Restitusi Kesehatan Pegawai / Pensiunan

Proses pembayaran restitusi atau penggantian pengobatan kepada pegawai/pensiunan pembayarannya dilakukan di UPI melalui sistem ERP PLN.Proses pembayaran restitusi kesehatan pegawai/pensiunan diawali dengan penerimaan Surat Permohonan Pembayaran dari Manajer UPI ke Manaje Keuangan UPI .Selanjutnya proses diakhiri dengan release transaksi oleh pejabat fungsi keuangan dan transfer restitusi kesehatan kerekening bank pegawai/pensiunan.

3. Pembayaran Biaya Perjalanan Dinas Pegawai 
Proses Pembayaran biaya perjalanan dinas terhadap pegawai pembayarannya dilakukan di UPI melalui sistem ERP PLN, proses pembayaran perjalanan dinas pegawai diawali dengan pengiriman daftar SPPD dari bidang SDM kepada bidang keuangan dan diakhiri dengan proses release oleh pejabat fungsi keuangan serta transfer pembayaran ke rekening bank pegawai

Untuk mengatasi terjadinya hambatanhambatan tersebut, maka Assisten Officer Administrasi SDM PT. PLN (Persero) P3B Jawa Bali APP Durikosambi melakukan usaha-usaha sebagai berikut:

1. Sebelum meng-upload data ke dalam program system application and product in data processing (SAP) sebaiknya dilakukan pengecekkan atas kelengkapan atau kebenaran dari data-data yang telah dimasukan.

2. Agar tidak terjadi keterlambatan dokumen yang dilakukan oleh karyawan perusahaan, maka perlu dibuatkan suatu sistem komputerisasi yang dihubungkan langsung ke aplikasi SAP.

3. Untuk menghindari jaringan yang sering eror, mengusulkan kepada bidang teknologi informasi untuk menambah kapasitas bandwidth jaringan ke PT ICON+ melalui Unit Induk.

4. Unit induk akan melakukan penguncian program system application and product in data processing (SAP) pada saat posting/running data karena untuk menghindari gagal upload pada proses posting dan agar proses yang dilakukan bisa berjalan dengan lancar.

5. Karena sebagian dari para pegawai mempunyai keterbatasan dalam bahasa asing, maka PT. PLN (Persero) P3B Jawa Bali APP
Durikosambi sering mengadakan suatu pelatihan untuk para pegawai agar bahasa-bahasa asing yang terdapat dalam program system application and product in data processing (SAP) dapat dikuasai dengan baik.

\section{FLOWCHART}

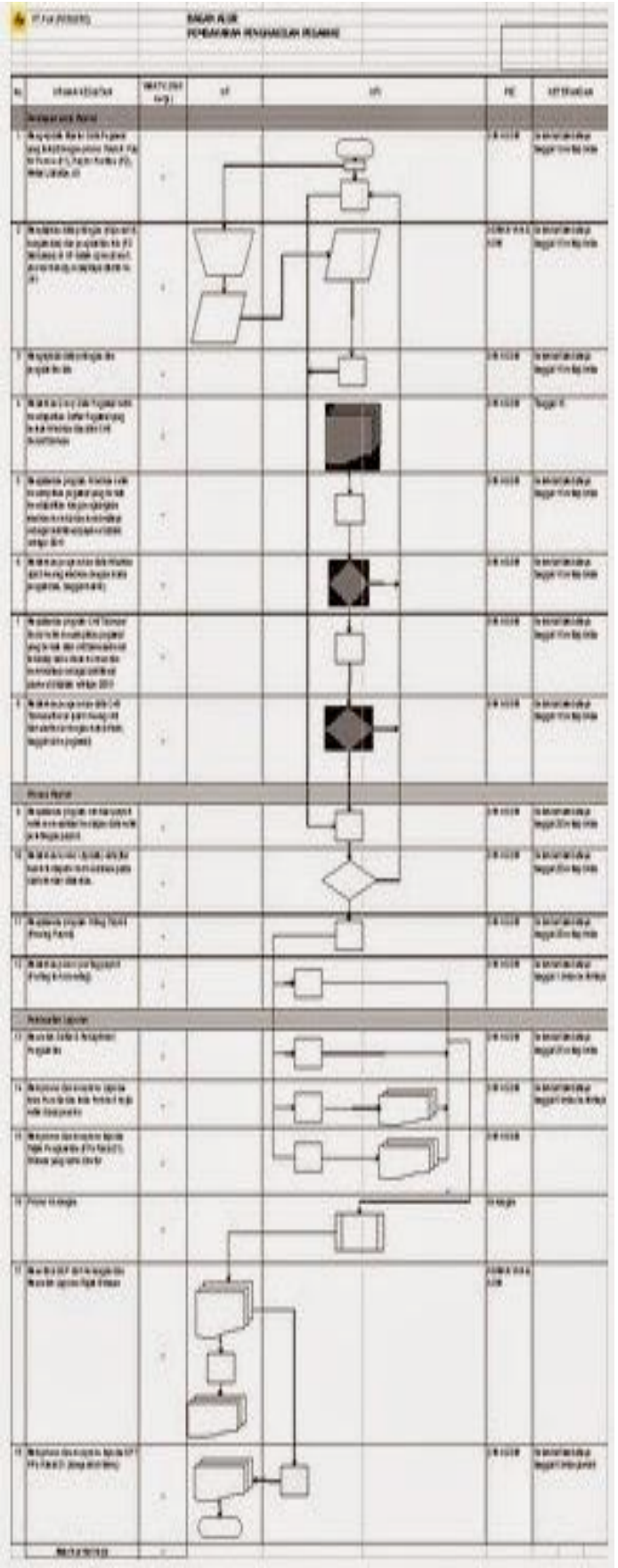




\author{
PublicClassMenu Utama \\ PrivateSub \\ UserToolStripMenuItem_Click(ByVal \\ sender As System.Object, ByVal e As \\ System.EventArgs) Handles \\ UserToolStripMenuItem.Click \\ Users.Show() \\ EndSub \\ PrivateSub
}

PegawaiToolStripMenuItem_Click(ByVal sender As System.Object, ByVal e As System.EventArgs) Handles

PegawaiToolStripMenuItem.Click

Pegawai.Show()

EndSub

PrivateSub

SetingJamToolStripMenuItem_Click(ByV al sender As System.Object, ByVal e As System.EventArgs)

SetingJamToolStripMenuItem.Click

SetingJam.Show()

EndSub

PrivateSub

AbsensiMasukToolStripMenuItem_Click(

ByVal sender As System.Object, ByVal e As System.EventArgs)

AbsensiMasuk.Show()

EndSub

PrivateSub MenuUtama KeyPress(ByVal sender AsObject, ByVal e As System.Windows.Forms.KeyPressEventAr gs) HandlesMe.KeyPress

If e.KeyChar $=\operatorname{Chr}(27)$ ThenEnd

EndSub

PrivateSub MenuUtama_Load(ByVal sender As System.Object, ByVal e As System.EventArgs) HandlesMyBase.Load EndSub

PrivateSub

KeluarToolStripMenuItem Click(ByVal sender As System.Object, ByVal e As System.EventArgs) Handles

KeluarToolStripMenuItem.Click

End

EndSub

PrivateSub

AbsensiKeluarToolStripMenuItem_Click( ByVal sender As System.Object, ByVal e
As System.EventArgs) Handles AbsensiKeluarToolStripMenuItem.Click AbsensiKeluar.Show()

EndSub

PrivateSub

AbsensiManualToolStripMenuItem_Click( ByVal sender As System.Object, ByVal e As System.EventArgs) Handles AbsensiManualToolStripMenuItem.Click AbsenManual.Show()

EndSub

PrivateSub Button6_Click(ByVal sender As System.Object, ByVal e As System.EventArgs)

AbsenManual.Show()

EndSub

PrivateSub Button1_Click(ByVal sender As System.Object, ByVal e As System.EventArgs) Handles Button1.Click Users.Show()

EndSub

PrivateSub Button2_Click(ByVal sender As System.Object, ByVal e As System.EventArgs) Handles Button2.Click Pegawai.Show()

EndSub

PrivateSub Button3_Click(ByVal sender As System.Object, ByVal e As System.EventArgs)

Button3.Show()

EndSub

PrivateSub Button4_Click(ByVal sender As System.Object, ByVal e As System.EventArgs)

AbsensiMasuk.Show()

EndSub

PrivateSub Button5_Click(ByVal sender As System.Object, ByVal e As System.EventArgs) Handles Button5.Click AbsensiKeluar.Show()

EndSub

PrivateSub Button7_Click(ByVal sender As System.Object, ByVal e As System.EventArgs) Handles Button9.Click LaporanMaster.Show()

EndSub

PrivateSub Button8_Click(ByVal sender As System.Object, ByVal e As System.EventArgs) Handles Button10.Click 
LaporanAbsensi.Show()

EndSub

PrivateSub Button9_Click(ByVal sender As System.Object, ByVal e As System.EventArgs) Handles

Button11.Click

End

EndSub

PrivateSub

DataMasterToolStripMenuItem_Click(By

Val sender As System.Object, ByVal e As

System.EventArgs)

Handles

DataMasterToolStripMenuItem.Click

LaporanMaster.Show()

EndSub

PrivateSub

DataTransaksiToolStripMenuItem_Click(

ByVal sender As System.Object, ByVal e

As System.EventArgs) Handles

DataTransaksiToolStripMenuItem.Click

LaporanAbsensi.Show()

EndSub

PrivateSub

TidakHadirToolStripMenuItem Click(By

Val sender As System.Object, ByVal e As

System.EventArgs)

Handles

TidakHadirToolStripMenuItem.Click

TidakHadir.Show()

EndSub

PrivateSub Button10_Click(ByVal sender

As System.Object, ByVal e As

System.EventArgs) Handles Button6.Click

TidakHadir.Show()

EndSub

PrivateSub

TransaksiToolStripMenuItem_Click(ByVa

1 sender As System.Object, ByVal e As

System.EventArgs)

TransaksiToolStripMenuItem.Click

EndSub

PrivateSub Button4_Click_1(ByVal sender

As System.Object, ByVal e As

System.EventArgs)

SetingJam.Show()

EndSub

PrivateSub Button5_Click_1(ByVal sender As System.Object, ByVal e As System.EventArgs) Handles Button7.Click EndSub

EndClass

\section{KESIMPULAN DAN SARAN}

\section{Kesimpulan}

Berdasarkan dari hasil dan pembahasan dalam penelitian yang dilakasanakan pada PT. PLN (Persero) P3B Jawa Bali APP Durikosambi, maka penulis mampu menarik kesimpulan sebagai berikut:

1. Proses Pembayaran gaji pegawai dengan System Application and Product in Data Processing (SAP) pada PT. PLN (Persero) P3B Jawa Bali APP Durikosambi yang dilaksanakan sudah cukup baik walaupun masih banyak masalah yang dihadapi dalam proses pembayaran biaya pegawai terpusat dengan sistem system application and product in data processing (SAP).

2. Kebijakan mengenai penggajian telah sesuai dengan UMR (Upah Minimum Regional) yang telah ditetapkan oleh pemerintah untuk meningkatkan kesejahteraan karyawan dilihat dari adanya pemberian tunjangan-tunjangan, biaya kesehatan, uang lembur dan lain sebagainya.

3. Dari beberapa hambatan-hambatan yang diketahui penulis dalam proses pembuatan dan pembayaran gaji pegawai, terdapat masalah yang sulit ditemukan solusinya oleh para pegawai pada PT. PLN (Persero) P3B Jawa Bali APP Durikosambi khususnya pada bagian SDM seperti pada saat unit induk mengunci program System Application and Product in Data Processing (SAP) yang dilakukan selama kurang lebih tiga hari, para pegawai tidak dapat melakukan apapun selain menunggu sampai program System Application and Product in Data Processing (SAP) 
tersebut dibuka kembali oleh unit induk.

Menurut penulis hambatan yang mudah untuk ditemukan solusinya adalah pada saat para pegawai kurang memahami katakata dalam bahasa asing, maka dari itu PT. PLN (Persero) P3B Jawa Bali APP Durikosambi mengadakan pelatihan untuk mempelajari kata-kata dalam bahasa asing yang terdapat pada software System Application and Product in Data Processing (SAP), walaupun sebenarnya sanngat sulit bagi para pegawai mempelajarinya karena faktor usia tetapi perusahaan sudah berusaha untuk memperbaiki kekurangan yang dimiliki perusahaan.

\section{Saran}

Dari hasil tinjauan dan analisa penulis selama melaksanakan penelitian di PT. PLN (Persero) P3B Jawa Bali APP Durikosambi, penulis ingin memberikan saran dan masukan untuk bahan pertimbangan PT. PLN (Persero) P3B Jawa Bali APP Durikosambi, yaitu:

1. Sistem dan proses pembayaran biaya pegawai terpusat dengan menggunakan softwaresystem application and product in data processing (SAP) pada PT. PLN (Persero) P3B Jawa Bali APP Durikosambi sudah cukup baik, untuk itu sebaiknya perusahaan dapat mempertahankan sistem dan prosedur yang sudah berjalan. Dan diharapkan untuk meningkatnya menjadi lebih baik.

2. Diperlukan ketelitian para pegawai dalam meng-input data pada software System Application and Product in Data Processing (SAP) untuk menghindari kesalahan dan gagal upload dalam pembayaran gaji kepada pegawai.

3. Perlu ditingkatkan koordinasi yang baik dari bagianbagian yang terlibat dalam proses perhitungan dan pembayaran biaya pengawai kepada para pegawai, dan diharapkan setiap bagian yang terlibat agar meningkatkan kedisiplinan, sehingga tidak akan menghambat proses pembayaran kepada pegawai.

\section{DAFTAR PUSTAKA}

1. Anggoro Rudy Lud. Februari 2013. "Analisa Tingkat Absensi Terhadap Produktivitas Kerja dan Penentuan P3-1". Sumatera:telaan staff PT.PLN (Persero) UIP Jaringan Sumatera I

2. Elisabeth Kartika, Eka Widhi Yunarso, dkk. 2011," Sistem Informasi Absensi Dan Penggajian Karyawan (studi kasus:PT.Kimia Farma)". Bandung. Penelitian Program Program Studi Manajemen Informatika Politeknik Telkom Bandung.

3. Mulyandi Rachman, Cynthia Ayu Wulan Dini. Januari 2014. "Aplikasi Absensi Pegawai Kecamatan Batuceper Tangerang Dalam Meningkatkan Akurasi Informasi". Tangerang. Jurnal CCIT. Vol 7 No 2.

4. Sari Anas Fitri Catur, Lies Yulianto. Maret 2013. "Perancangan Sistem Informasi Absensi Menggunakan Finger Print di Badan Perencanaan Pembangunan Daerah dan Penanaman Modal Kabupaten Pacitan". Surakarta. Seminar Riset Unggulan Nasional Informatika dan Komputer FTI UNSA 2013. Vol 2 No. 1.

5. Supriyono Joko, 2014. "Perancangan Sistem Informasi Absensi Karyawan Menggunakan Konsep Data Mining Pada PT. Kalila Indonesia". Skripsi Raharja: Tangerang 
6. Rukmianti Dhita. 2010. Pengembangan Sistem Informasi Absensi Pegawai PadaPerguruan Tinggi Raharja, SKRIPSI Raharja: Tangerang.

7. UU Republik Indonesia NO 13 2003 Tentang Ketenagakerjaan

8. SK Direksi No SK. 1364. K. DIR. 2011 Tentang Implementasi Pemusatan Pengelolaan Fungsi Administrasi Keuangan, Administrasi Sumber Daya Manusia dan Administrasi Umum Dari Unit Pelaksana ke Unit Pelaksana Induk.

9. Edaran Direksi No 014.E/DIR/2011 Tanggal 17 Oktober 2011 Tentang Pedoman Implementasi Pemusatan Pengelolaan Fungsi Administrasi Keuangan, Administrasi Sumber Daya Manusia dan Administrasi Umum Dari Unit Pelaksana ke Unit Pelaksana Induk Modul SAP HR PT.PLN (Persero). 